\title{
After Seattle: free trade and the WTO
}

\author{
JAGDISH BHAGWATI
}

\section{The outlook for world trade: bad news, good news}

The multilateral trading system at the millennium finds itself in the dizzying aftermath of a rollercoaster ride, with bad and good news coming at us in tandem and in spades.

The bad news has come mainly from Washington, both the city and the state. President Clinton failed to get fast-track authority, virtually a requirement for negotiating big trade agreements from Congress. The WTO meeting in Seattle, held from 27 November to 3 December 1999, wound up in chaos. At the OECD, the Multilateral Agreement on Investment (MAI) ran aground over French withdrawal of its consent, prior to Seattle, giving NGOs a victory that only added electricity and energy to their anti-trade agitations. There has, in consequence, been a sense of despair among some of the pro-trade groups in the United States: if trade is such a difficult case to sell at a time of unprecedented prosperity and employment, what could happen when the economy turns down — as it almost certainly will, some day?

On the other hand, the anti-globalist NGOs, politicians and labour unions can no longer talk of an unending stream of victories against the freeing of trade. The vote on China's entry into the WTO was critical in this context, since it was won against an intensive campaign of opposition, waged especially by most unions and the AFL-CIO, and also by some influential NGOs like Ralph Nader's Public Citizen; and it was also won even though China is about the worst country that you can point to if you wish to argue against freer trade on moral grounds (as many unions like to do, whether the true reason be moral or protectionist): it is definitely off the curve, indeed way off the curve. Yet in the end this victory was important to the pro-trade groups only in the sense that a defeat would have made the victorious anti-trade groups ever more fierce and

This is a revised version of the Keynote Address delivered at Kennedy School, Harvard University, at a conference in memory of Ray Vernon on I June 2000. The original version will be published in Roger Porter, Pierre Sauve, Arvind Subramanian and Americo Zampetti, eds, Equity, efficiency and legitimacy: the multilateral system at the millennium (Washington DC: Brookings Institution Press, 200I). 


\section{Jagdish Bhagwati}

effective in the public domain. Its value in itself, as an indicator of a change in political sentiment in favour of free trade, is negligible, because the deal was astonishingly one-sided in terms of concessions: China made virtually all of them, the United States practically none. ${ }^{\mathrm{I}}$ No trade deal of that kind can be repeated: all 'normal' trade negotiations involve give as well as take.

Nor would I call the passage by the United States legislature in 2000 of the Africa Growth and Opportunity Act, which is in many respects a trade bill, a major indicator of a changed sentiment in favour of trade on Capitol Hill or in the country. As Arvind Panagariya and I noted in the Financial Times, ${ }^{2}$ this Act is a Trojan horse masquerading as a gift horse. Cast in the mould of preferential access, it extracts more than it gives. US lobbies, both protectionists and unions, have imposed restrictions and made successful demands for reverse preferences for the United States that make this Act an example of how not to liberalize trade for the poor countries. This again is surely not indicative of what genuine trade liberalization is about; and again it provides little indication of what political obstacles will confront the next major attempt at freeing trade or of what political leadership will be available to guide it. ${ }^{3}$

The really good news about trade, in my view, lies elsewhere. For example:

- Trade continued to grow in the last decade of the twentieth century, despite financial crisis in Asia and Russia, at a faster rate than incomes.

- During the financial crisis, trade barriers did not escalate sharply; indeed, except for some anti-dumping actions and Voluntary Export Restraints (VERs), on steel by the United States, in particular, plus some rise in tariffs towards their higher permitted levels (as with 504 items by Mexico after the November 1994 peso crisis), little increase in protectionism can be detected. Why is this? Partly thanks to the architects of GATT, who in drawing up the new arrangements for trade sought institutional mechanisms to prevent a recurrence of the rapid competitive raising of trade barriers that had broken out after the Great Crash in I929. They turned out to be right, and the GATT, or its successor the WTO, did work. In addition, of course, two other factors helped. First, the fact that the prevailing economic doctrine has changed to the view (espoused among others by policy-makers in several of the countries afflicted by the financial crisis) that macroeconomic adjustment is best undertaken not through trade but through macroeconomic policies, and that trade should be 'assigned' to, i.e. used instead to address, the gains-from-trade target. Second, that this view

I I do recognize, as do all good economists, that a trade 'concession' is generally good for oneself too. But my remarks here are made in the political context where one's own trade barrier reductions are considered to be a 'concession' against which every trade negotiator looks for 'concessions' by the other side.

2 Cf. Jagdish Bhagwati and Arvind Panagariya, 'A Trojan Horse for Africa', Financial Times, 30 June 2000.

3 By contrast, genuine and outright MFN liberalization of products of the greatest interest to the poor African countries, with aid and technical assistance provided to enable the countries to take advantage of the trading opportunities created, would have made more sense. 


\section{After Seattle}

was also the basis of conditionality in the grant of extraordinary assistance from the Bretton Woods institutions in Washington during the crisis.

- Trade will grow in the next few years, even without any new negotiations in the form of a new WTO round, partly because the fruits of the Uruguay Round (UR) are still being harvested. Not only are services and agriculture being negotiated as part of the unfinished UR agenda — and these areas will surely yield some progress, even if slowly-but concessions on the MFA, which are end-loaded, are still to materialize. Also, the vastly more effective dispute settlement mechanism continues to open markets: for example, India lost its Article I 8(b) case to the United States and is now beginning to remove its balance-of-payments quota restrictions (which are permitted by GATT, Article I8(b) on the grounds of balance-of-payments difficulties) on consumer goods imports.

- Finally, we should not lose sight of the fact that trade negotiations are not necessarily the only route to lower trade barriers. Countries worldwide have unilaterally reduced trade barriers in the past two decades, outside the framework of trade negotiations (whether plurilateral or multilateral) characterized by reciprocity, because they have seen that these restrictions only hurt them. This process of 'unilateral trade liberalization' continues apace. ${ }^{4}$

\section{Why we still need to worry}

Notwithstanding these encouraging signs, I propose to argue that there are important reasons for continued concern about the prospects for trade. In discussing these reasons, we need to distinguish sharply between two sets of issues: those relating to free trade itself; and those concerning the WTO, our primary and reconstituted trade institution.

\section{Free trade}

Back in the late I980s and early I990s the challenges to the prescription for freeing trade came from the younger theorists, many of them my own students, principally Paul Krugman and Gene Grossman. When imperfect competition is present in the product markets, we see, as the Nobel Laureate John Hicks saw and wrote clearly over 40 years ago in 1959 in the aftermath of the great work 30 years earlier on monopolistic and imperfect competition of Edward Chamberlin and Joan Robinson in Cambridge (US) and Cambridge (UK) respectively, that the case for free trade is compromised. After all, it is in an essential sense dependent on whether market prices reflect social costs; and with imperfect competition, this is no longer so, generally speaking.

\footnotetext{
4 I have documented the reasons for this trend in a major research project on the subject, to be published in autumn $200 \mathrm{I}$ as Jagdish Bhagwati, ed., Going alone: the case for relaxed reciprocity in freeing trade (Cambridge, MA: MIT Press).
} 


\section{Jagdish Bhagwati}

The real problem was that this implication was presented to the public, not as an old insight that was now refined (in terms of precise policy implications for the nature of departure from free trade called for, these implications being drawn brilliantly by exploiting the latest advances in the theory of industrial organization, tools that were not available when Hicks was writing), but as a radical new insight into, and a powerful new dent in the case for, free tradewhich it surely was not. In fact, Paul Krugman, in his youthful surrender to irrational exuberance, went so far as to propagate the view that, in light of these theories, it was no longer possible now to defend free trade on theoretical grounds: a contention that had great political salience with protectionists but no scientific foundation whatsoever, since theoretical exceptions to free trade, for example on the grounds that atomistic competition in trade among nations was absent, went back at least to the late i840s. 5 Another gifted student of mine, who was clearing his desk, found and sent to me a paper by Krugman from those times that had been published in the magazine The International Economy, entitled: 'Protectionism: try it; you will like it'. All this work attracted enormous political exposure and gained currency because the time was ripe for a tilt towards protectionism, with the rise of Japan and the fear that the twentyfirst century would be the Pacific century.

That salience has now disappeared: the United States has triumphed and Japan has collapsed, at least for the time being. In these new circumstances, some participants in the debate have changed sides. I was surprised recently to hear Clyde Prestowitz, who was among the more vocal proponents of protectionism because of Japan's example and the fear that the United States would lose out to its eastern competitor if it did not imitate it, arguing on $m y$ team in favour of free trade in a televised debate on protection-prompting the opposing team leader, Robert Kuttner, to ask in anguish: 'Why have you deserted us?' Equally, the new theorists have finally come around to propounding free trade again, either because (like Grossman and Avinash Dixit) they buy into the argument that there is 'no beef', that is, that imperfections in the trading system are not sufficiently significant to amount to a justification for protectionism (a case not unlike that made by the Chicago school against interventionism inspired by the emergence in the I930s of imperfect competition theories), or because (like Krugman) they argue that intervention will make things worse (an argument that is actually more 'conservative' and associated less with Chicago than with the public choice school). Also, the feeling has grown among economists that, owing to several possible factors including the x-efficiency effects of competition and the benefits from exploiting scale economies, free trade can bring big gains and protection correspondingly big losses.

5 This is the famous 'optimal tariff' argument when firms are competitive but nations have monopoly power, and is of course associated with Robert Torrens. The question of monopoly power at the level of the firm instead was taken up in the I930s, as noted above. 


\section{After Seattle}

So, less than a decade after the burst of sentiment in favour of protectionism, the case for free trade currently stands in fine shape as far as the 'conventional' challenges from within the profession and from the motley crew of Japanfearing or Japan-admiring politicians, bureaucrats, journalists and others in the public policy domain are concerned. But this is not the whole picture; the scene has become populated with a whole new set of opponents of free trade, and often of 'globalization' in some broad and general sense.

\section{The medley of new complaints}

The new complaints range over a very wide arena. First, trade is said to be $a$ threat to culture. M. Bove of France (the well known French activist), a new hero on the French streets, has fused culture with agriculture-marrying conventional protectionism with the protection of culture-in a populist and powerful objection to further trade liberalization, prompting M. Pascal Lamy (the EU Commissioner for Trade) into proclaiming the 'multi-functionality' of agriculture as a fact not to be forgotten in freeing agriculture from protection. The Canadian Minister of Culture has taken nearly two dozen of her counterparts in other nations down the road of alarm over the cultural threats posed by trade and globalization.

Second, trade is said to harm the environment. The I99 I episode in which tuna fishing was said to be causing severe damage to dolphin populations has been succeeded by other cases, chiefly a similar argument involving damage to turtles in the course of shrimp harvesting, throwing into sharp relief the conflict that can arise between the desire to open up market access and the desire to restrict it on the basis of values unrelated to trade. There are also potential conflicts between the trade restrictions contemplated in the Multilateral Environmental Agreements (against 'free riders' and defectors) and those implied by the WTO, which need clarification and reconciliation. These conflicts, while generated often by institutional questions relating to the WTO, have spilled over into the case against free trade itself.

Third, trade is said to override human rights and labour rights. It is, incidentally, somewhat amusing that human and worker rights are listed additively by the activists, as if 'human' did not embrace 'workers', and the latter were merely robots. In any event, both human rights activists and labour unions are up in arms against free trade, arguing that it overrides 'values' and undermines the attainment of better standards. Both groups aim at putting restraints on free trade. The agitators also believe, for the most part, that trade (and direct foreign investment, i.e. multinational corporations) must be faulted for the accentuation of poverty worldwide, instead of being a principal component of a strategy to reduce it.

I shall presently turn to a necessarily brief examination of some of these "trade and-' types of complaints. ${ }^{6}$ But, first, I would like to take the opportunity

\footnotetext{
6 I have done this more fully over the last several years, both in the public arena and in scholarly work such as the two substantial volumes edited by Professor Robert Hudec and myself under the title Fair
} 


\section{Jagdish Bhagwati}

briefly to consider two common fallacies that produce much of the heat against free trade. ${ }^{7}$ The first relates to the common tendency to assume that if the (imprudently hasty) freeing of financial flows played a major role in precipitating the Asian financial and economic crisis, arguably the biggest humaninduced economic disaster since the Smoot-Hawley tariff of I930 (which brought the US tariff to the highest protective level yet in the history of the US), then free trade is equally to be condemned. That is a non sequitur, of course; but its appeal to the anti-globalists is so strong that even so accomplished an economist as Dani Rodrik succumbed to it in his recent essay in The New Republic, 'The Global Fix', where he started with the financial crisis and proceeded illogically to fix the trade system instead. Arguing for free trade in the public domain is difficult enough without having to carry the burden of being accused of playing for freewheeling gung-ho financial capitalism at the same time.

The second problem arises because of the widespread concern with poverty that now animates both the streets and the international institutions. For those of us who come from India, the notion that such concerns automatically imply sensible diagnoses and effective policies is not compelling. Indian planners, politicians and economists have talked of little else since the I950s. Contrary to James Wolfensohn's belief that he and his advisers have had the supreme virtue of discovering poverty where his predecessors and others were ignorant or indifferent or both, poverty reduction was at the centre of development economists' and indeed Indian planners' attention from the outset of the postwar developmental efforts. Yet poverty failed to decline significantly in India until the abysmally low growth rates of a quarter-century, produced for the most part by illiberal, anti-market and anti-globalization policies, compounded by a persistent attachment to an inefficient public sector and to white elephants employing capital-intensive techniques, were reversed, beginning in the I980s and in a more decisive and sustainable fashion in the i990s. The fallacy that dominates the public scene today, especially among the anti-globalists and the politicians who pander to them, is that talking about poverty is tantamount to reducing it. Talk comes cheap; the hard part is getting the policies right. The easy and populist tendency today, to denounce pro-market, pro-free-trade policies as the cause of persistent poverty in both poor and rich countries when, in fact, it is possible to argue forcefully that they are part of the solution, not just on an a priori basis but also on the basis of convincing evidence, is yet another cross for the proponents of free trade to bear.

As for the 'trade and-' concerns regarding environment et al., the way to cut through many of them is to remember just a few principles from the

trade and harmonization: is fair trade a prerequisite for free trade? (Cambridge, MA: MIT Press, I996), which provided the first comprehensive analysis of these 'trade and-' issues by a research team of trade economists and lawyers that laboured over the questions for three years.

7 There are several others that I have discussed in my recent review essay, 'Globalization in your face', Foreign Affairs, 79:4, July/August 2000, pp. I34-9. 


\section{After Seattle}

volumes on 'fair trade' cited in note 6 above, and also from the revolutionary insights from the postwar literature on the theory of commercial policy, in particular the theory of optimal intervention under distortions in an open economy. ${ }^{8}$ In particular, I would like to focus here on two 'fair trade' arguments and two 'distortions'-related principles.

\section{Fair trade}

The two 'fair trade' arguments with particular political salience are that if your rivals have lower environmental and labour standards than you have, (I) they are indulging in 'social dumping' which needs to be countervailed by a tariff and/or (2) there will be a 'race to the bottom' which will leave you with lower standards than you want. Neither argument is compelling, however. Differences in standards typically reflect differences in fundamentals: in your initial conditions, your endowments and preferences. Thus, even given identical desires to prevent domestic pollution per se, and shared acceptance of the 'polluter pay principle', the pollution tax rates for identical carcinogens dumped into the local waters or the air can be fully expected to differ across countries.? Diversity of tax burdens is totally legitimate; to call it 'unfair' competition is to betray ignorance of elementary economics - a charge which can be laid at the door of Messrs Bonior, Boren, Gephardt and Gore, all leading American politicians in the Democratic Party who have written erroneously on the subject and most of whom have also sought to legislate on the basis of their misguided convictions.

By contrast, the 'race to the bottom' argument is theoretically a valid one; where it fails, in my view, is in its empirical relevance. An uncoordinated Nash equilibrium could well produce, under second-best conditions, outcomes where each country or a subset of countries will fall short of either or both economic welfare and environmental goals compared to what a coordinated equilibrium would achieve. But that is not to say that this coordinated equilibrium will be characterized by the lower-standard countries in the Nash equilibrium moving up the scale-let alone duplicating the levels currently in vogue in the United States, for example. Indeed, the economist John Wilson has shown that the world may even be characterized by a race to the top, not to the bottom.

But the real problem is not theoretical. It is simply that we have little evidence either that governments actually run the race (i.e. choose to attract investments) by offering to cut standards, or that multinational corporations are actually attracted by such concessions and are therefore joining in such a race. A

8 This theory goes back to the article I wrote with V. K. Ramaswami in I963, published in the Journal of Political Economy ('Domestic distortions, tariffs, and the theory of optimum subsidy', vol. 7I, pp. 44-50) and the subsequent work of several economists such as Harry Johnson, Max Corden and T. N. Srinivasan.

9 I am talking, of course, of pollution confined to the country, i.e. to domestic pollution, and not to crossborder pollution. I am also abstracting from the notion of 'values'-related objections to granting market access, which raises other issues. 
great deal of empirical evidence suggests that multinationals do not choose environmentally unfriendly technologies, for example, or even locations where the environmental regulations are less stringent. ${ }^{\text {IO }}$ Moreover, the race to the bottom occurs far more in another space: in tax concessions offered by governments (including local and state governments in federal countries) to attract multinationals. Few governments, certainly now that democracy has broken out worldwide, are likely to say instead to multinationals: come and make profits by polluting our waters and air!

My own view is that, since there is little evidence of multinationals (who account for the bulk of direct investment, as distinct from small firms) choosing to exploit lower environmental standards, we should simply extend our standards (as distinct from wages, of course) to our firms abroad, on a mandatory basis: do in Rome as New Yorkers do, not as Romans do. This would assuage the fears of the environmentalists, and of those seeking dignity and safety for workers abroad, without imposing serious constraints that these firms do not already impose on themselves. Alongside this mandatory action, I would also encourage the growth of several voluntary codes, such as the Social Accountability Label, SA80oo, on whose Board I serve, and which is now in business with over 50 factories certified in 2 countries.

The mandatory codes will naturally differ across the countries that adopt them since they merely reflect an extension of national codes and laws; the voluntary codes differ among themselves but are identical across countries for everyone who signs on to them. Between them, they provide a splendid and more efficient and equitable alternative to the demands for anti-'social dumping' import duties that would offset 'unfair trade' and for legislation aimed at preventing a hypothetical race to the bottom.

\section{Principles of commercial policy}

If some of our leading politicians are succumbing to the proponents of 'fair trade' in regard to demands for a 'social tariff' and other measures on the basis of dubious, indeed bad, economics, as I have just argued, their lack of comprehension of the central prescriptions of postwar developments in the theory of commercial policy accounts for further misguided policy confusions that imperil the cause of free trade. Let me concentrate on just two of these confusions: first, the notion that free trade, relative to protection, harms causes such as the environment; and second, that the use of trade sanctions is necessary to advance (altruistically) social agendas such as good labour standards abroad. ${ }^{\text {I I }}$

Io This was the burden of Arik Levinson's well-known research, reviewed in his contribution to Bhagwati and Hudec, Fair trade and harmonization, vol. I. T. N. Srinivasan and I (ch. 4) offer a number of reasons why multinationals may be indifferent to making more money by playing down to lower standards. However, a couple of recent studies, looking at alternative locations in close proximity in the United States, suggest that there is some sensitivity to lower standards in firms' choice of locations.

II The 'fair trade' arguments for suspending trade access, if standards are lower abroad, relate to 'egotistical' (i.e. own-interest) reasons, whereas the argument that such suspension of trade access is undertaken to advance social agendas abroad is based instead on 'altruism'. This distinction is absolutely critical and 


\section{After Seattle}

We know clearly now, from the theory of intervention under distortions (i.e. market failures) that two principles must be kept in mind:

- If the market failure is not fixed by suitable policy - and that policy is domestic when the market failure is in domestic markets - then free trade in the presence of such a distortion may be worse than (a given level of) protection; but so may that protection vis-à-vis free trade.

- If you fix the market failure through suitable policy intervention, then free trade regains its claim as the necessarily appropriate welfare-improving policy.

These principles sound straightforward to most economists today; but they were revolutionary when developed in the I960s because until then-indeed, for nearly two centuries after Adam Smith's Wealth of nations and the simultaneous discovery of the Invisible Hand and the case for free trade-economists had always conceded that, for varying types of market failure, the case for free trade collapsed and therefore knee-jerk protectionism could not be ruled out.

Apply them, then, to the environmentalists' agitation against free trade, starting at the beginning of the I990s, which simply assumed that if you did not have a good environmental policy (e.g. the 'polluter pays principle' was inoperative), free trade was no longer appropriate. The first principle above shows that (any given level of) protection may be worse, not better, than free trade. Thus the I99I GATT Report on Trade and the Environment (which I, as economic policy adviser to Arthur Dunkel at the GATT, helped to write) showed, for the education of the militant environmentalists, that in two empirical cases, leaving environmental policies at their presumably inefficient level, freeing of trade could be demonstrated to improve both economic welfare and the environment.

At the same time it follows that if (say) the polluter pays principle is followed, and the market failure (in the sense of absent markets where pollution can be priced and paid for) is therefore fixed by suitable governmental intervention, we can be confident that economic welfare will be enhanced by free trade and that environmental considerations will also have been dealt with appropriately.

This latter principle, that we should have a suitable market-failure-eliminating policy to go with free trade, can be seen also from another vantage point, namely, that if you have two targets, you will generally require two instruments to achieve them optimally. In plain words, you cannot kill two birds with one stone. In short, if the environment has to be looked after, and the gains from trade increased or maximized, then both an environment policy and a free trade policy will be needed.

\footnotetext{
leads to very different argumentation as to why the advocacy of trade sanctions, i.e. restriction of trade access, is to be deplored. I have dealt with these distinctions at length in my recent paper on the subject of linkages, reprinted chapter in my selection of essays, The wind of the hundred days: how Washington mismanaged globalization (Cambridge, MA: MIT Press, 200I).
} 


\section{Jagdish Bhagwati}

This principle also extends, except for necessary interfaces, to institutional design (such as the compatibility of permissible trade restrictions in Multilateral Environmental Agreements and their inadmissibility under WTO rules). Should an issue like accelerated reduction of child labour be taken to the ILO or be dealt with at the WTO and through other trade treaties and with trade sanctions? Many (including myself) have argued that pursuing social agendas through trade treaties and institutions, with trade sanctions (as implied by a Social Clause at the WTO, for instance, which in fact, is the reason why its proponents want it introduced there), amounts to an attempt to use one stone to kill two birds: the freeing of trade and the advancement of social agendas. In fact it will entail our missing both birds: freeing of trade will be slowed down and the advancement of social agendas will be impaired.

President Clinton's problems - the failure to renew fast-track authority and the Seattle debacle-are to be attributed to this very issue; they both slowed down freeing of trade, the former due to resulting dissensions at home between Democrats and Republicans and the latter due to overriding differences on the Social Clause vis-à-vis the developing countries. At the same time, the morality of the agenda has itself been devalued because, for several reasons including the selectivity bias against the developing countries in the choice of items included in the Social Clause, most of these countries (including their intellectuals and NGOs) now see the use of moral arguments to justify the Social Clause and the attendant trade sanctions as a thinly disguised attempt at moderating competition from the developing countries in labour-intensive products.

It makes more sense to develop another stone, perhaps even several pellets with the total force of a stone's throw. That is what the proposals to pursue these agendas through appropriate and appropriately strengthened agencies such as the ILO, and with policy instruments other than trade sanctions, are about. Indeed, going after widespread child labour (which is surely necessitated predominantly by poverty in many countries) with trade sanctions is like training an AK-47 on a stadium packed with students at a pot-smoking weekend rock concert because you think they should be at work instead; it is outrageously inappropriate. The heavy lifting that is necessary to accelerate the reduction of child labour, requiring efforts involving governments, NGOs and aid agencies, all working at the ground level, contrasts decisively with the combination of 'gotcha' and protectionist mentalities that is currently rampant in labour unions and in fact is totally inappropriate to the job at hand.

I believe that this is also the way to answer Pascal Lamy's demands for the US (and especially the Cairns group) to look at the 'multi-functionality' of agriculture. Many cynics think that M. Lamy's ambitiously comprehensive agenda for a new WTO round, and the argument about multi-functionality, are simply fences being put up to prevent another round closing in on European agricultural protection. But there may be another, less cynical reason for $\mathrm{M}$. Lamy's preference for so ambitious an agenda: he seems to have inherited it from Sir Leon Brittan, and bureaucratic inertia at the European Commission 


\section{After Seattle}

might well have been a reinforcing factor in M. Lamy's position. On the 'multifunctionality' of agriculture, there is a simple answer, again from the basic principles of commercial policy. We should be able to find suitable policies which promote the other functions of agriculture while freeing trade; thus greenery could be subsidized directly rather than indirectly, and inefficiently, through trade barriers protecting agricultural production.

In the same way, the 'trade and culture' conflict is amenable to similar solutions based on the doctrine of matching the number of instruments with policies. Rather than protect French cinema by restricting the showing of Hollywood movies - a doomed 'solution' in any case, given the existence of VCRs - why not subsidize it? Let free trade in, so consumers can choose; and the resulting competition between Renoir and Spielberg is also likely to be artistically bracing.

\section{The WTO at risk}

It is astonishing therefore how many of the conflicts in the political domain over free trade can be resolved amicably, and to advantage, by invoking the basic insights of the modern theory of commercial policy. But the problems that have arisen regarding the WTO itself are another matter. They need urgent attention. So what are they?

To understand them, it is absolutely essential to recognize three main changes that have happened with the founding of the WTO:

- The WTO is increasingly under pressure from several lobbies - we must remember that NGOs are also lobbies - to move in the direction of introducing, just as it did with intellectual property protection, a variety of 'trade-unrelated' preconditions for market access, whereas the GATT was relatively free from such extraneous but powerful issues.

- Unlike the GATT, which was a very weak organization institutionally, with optional codes and a non-binding dispute settlement mechanism, the WTO is now a single undertaking (where a member must sign up to virtually everything) and has a binding dispute settlement mechanism.

- The demands to change the WTO, along with other international agencies, so as to accommodate greater transparency and participation by nongovernmental actors, have multiplied, indulged by mainly rich-country politicians who drift with, rather than challenge and shape, the situation.

The trade-unrelated issues: daggers aimed at the developing countries

The Uruguay Round saw the WTO turn into a tripod, its three legs being the old GATT, the new GATS on services, and intellectual property protection. But the last leg really did not belong at all. If the only criterion for getting your issue into the WTO is that your issue affects trade, then virtually everything gets 


\section{Jagdish Bhagwati}

in; so the underlying principle defining those issues that are covered by a trade institution such as the GATT or the WTO has to be something different.

On reflection, that defining principle has to be that of mutual gain. For, noncoercive trade is precisely a mutual-gain phenomenon. Of course, if two parties liberalize trade, a third party can get hurt; so two principles of operation need to be introduced to ensure that a multi-country trade institution such as the WTO functions in greater conformity with the principle of mutual gain at least as far as the poorer members, the developing countries, are concerned.

First, if a major trade negotiation (such as the Uruguay Round) is demonstrated as affecting adversely a specific group of developing countries (as Africa was affected by the Uruguay Round, according to several calculations), then the Bretton Woods institutions such as the World Bank and the IMF should be automatically scheduled to provide supplementary short-term finance for adjustment and long-term concessionary loans to cushion the blow. Second, if a dispute settlement panel or appellate court finding implies a major adverse sideimpact on developing countries, as in the bananas case where small Caribbean countries will suffer large losses, then again the Bretton Woods institutions must be simultaneously harnessed to cushion the impact. Indeed, in both cases bilateral aid agencies also should be primed into a triggered response with grants.

But, the principle of mutual gain simply does not obtain in any significant degree for intellectual property protection, which was worked into the WTO simply because of intense lobbying pressures in the United States from the pharmaceutical and software industries. Instead of mutual gain, IPP is pretty close to an unrequited transfer of royalties from the using to the producing countries. In effect, its inclusion turned the WTO into a royalty-collection agency: its trade sanctions were to be put at the disposal of the IP-producing countries.

Few economists at the time opposed this, some through indifference to and ignorance of what was going on, others because they were impatient to close the Uruguay Round after over seven years of negotiation and a disturbing mood of anti-multilateralism in the air. ${ }^{\mathrm{I} 2}$ Now that we have introduced something wholly contrary to the essence of a trade institution into the WTO, that third leg of the tripod has naturally attracted attention. The labour unions say: you did it for capital, so you must do it for labour. The environmentalists say: you did it for capital, so you must do it for nature. The door is wide open to everyone who can muster enough voices in the public space. As a result, the third leg is now in danger of growing ever more legs: the tripod is in danger of turning into a centipede. And the centipede will slow down progress to trade liberalization-because these trade-unrelated (in the sense just stated) issues have been defined and brought to the WTO by rich-country NGOs and other lobbies. Developing countries see IPP as a dagger aimed at them; they see these other demands in a similar light. For instance, the proponents of the Social

I2 I was perhaps the only one to raise serious objections from I990 on, including in my Harry Johnson Lecture in London that year (published as The world trading system at risk, Princeton, NJ: Princeton University Press, I99I). 


\section{After Seattle}

Clause see the developing countries as defendants. I have yet to see any developed country seriously worried about being taken to the WTO; the contents and (within them) those issues selected for fast-track implementation (such as child labour) are always those where the developing countries are expected to be found wanting.

This has created a situation where the developing countries which had seen the GATT as a multilateral institution that in trade matters would defend the weak against the strong, the rich, now see the new WTO as turning under richcountry pressures into an assault on the weak on trade-unrelated matters. The Seattle street theatre, in which the over-nourished workers of the rich countries were demonstrating against the under-nourished workers of the poor countries and pretending that it was in the latters' interest, where turtles were preferred over poor fishermen by the young environmentalists who knew little better, where uncomprehending children were cynically made to march against the use of child labour in the poor countries that have no magic wand to support millions of children in poverty who work to support themselves and their families, and where street violence erupted against the delegates, including those from the poor countries: all this made the developing-country delegations ever more aware that the game at the WTO had changed against them-and that it was an unequal contest, because the unions and the NGOs wore halos around their heads, whereas the traditional protectionist lobbies were at least seen for what they were when they sought measures against the exports of the developing countries.

No wonder, then, that they walked away rather than broker a deal such as the innocent-sounding but potentially deadly attempt at getting a 'study group' going under WTO auspices, with or without other institutions' participation: the developing countries would not hear of it as long as the WTO was involved in any way. Besides, the notion that institutions such as the World Bank would play fair was not exactly appealing: Mr Wolfensohn talks a good deal about poverty in developing countries, but his fortunes depend on keeping donor countries happy. When did he last say, for instance, that IPP is harmful to the developing countries, or that the good governance he seeks in his client states must be matched by good governance in the rich countries, or that corruption in Washington is as offensive as corruption in the poor countries?

The WTO will not get off to a start with a new round until these tradeunrelated issues are shifted to other arenas; and indeed, as I have argued above, that is exactly what the basic principles of international trade theory suggest should happen.

\section{Introducing flexibility into the WTO}

The WTO also needs to lighten up. The single undertaking approach is probably a legacy of the bullying tactics that I witnessed in the United States as the Uruguay Round progressed. Countless bureaucrats and businessmen said at 


\section{Jagdish Bhagwati}

meetings I attended that if India, Brazil (etc.) will block IPP (etc.) we will form our own WTO and let them go where they belong: the wilderness. Section 30 I tactics were also in the air: play by the rules we wish to impose or else we hit you with retaliatory tariffs.

The single undertaking approach is now irreversible, in my view. But the dispute settlement mechanism can be separated from the notion that nations must always comply by vacating legislation. That notion invites unnecessary anti-WTO political responses. I liked the approach of the 30 I Panel, which essentially opposed the 30 I legislation but said that it was valid until used. That enabled the United States to declare that it had won, in that the legislation was not found in violation of WTO agreement, and the EU to see that in fact it had won because the use of the legislation was ruled WTO-incompatible and so the EU did not need to appeal against the decision. Political fallout in the United States was avoided, but nothing substantive was lost.

The remedies must also move away from large-scale trade retaliation, as occurred in the banana and hormone-fed-beef cases. That only disrupts huge quantities of trade and makes ever more people hostile to the WTO, which is seen as authorizing bullying tactics in the shape of trade disruption; it is especially inappropriate in cases where profound safety concerns are aroused. In this context, the carousel proposal in the US to rotate the targets of retaliation is absurdly counterproductive. I have long argued that the remedies should include a shift to a labelling scheme where acceptable and, where not acceptable, to cash compensation, which would amount to only a small fraction of the value of trade affected if estimated (as it should be) as the gains from trade lost rather than the total value of trade lost. That compensation in turn could be directed to the industry whose market access has been lost: the firms producing hormone-fed beef, for instance.

I have some sympathy for the view that the panels and the court must defer somewhat more to the political process instead of making law in controversial matters. I was astounded that the Appellate Court in effect reversed longstanding jurisprudence on PPM (process and production methods) in the shrimp-turtle case. I have little doubt that the jurists were reflecting the political pressures brought to bear by the rich-country environmental NGOs and essentially making law that affected the developing countries adversely, and in the process increasing the latters' disquiet over the anti-developing-country turn they fear the WTO to be under pressure to take. Unless the WTO legal process understands that NGOs do not necessarily speak for developing countries, contrary to their assertions, the WTO will stand in danger of accentuating the problems of the North-South divide that are opening up so sharply after Seattle. 


\section{After Seattle}

\section{Transparency and participation}

Finally, there is the question of transparency and participation by civil society groups. For the WTO, we need to distinguish among three components of the organization: the working of the secretariat; the trade negotiations; and the dispute settlement mechanism. Each requires a different approach.

The dispute settlement process is now legal rather than political; so clearly it should be open. But matters such as amicus (friends-of-the-court) briefs raise difficulties. If they can be sent in only after standing is allowed (i.e. status is granted to appear before a court), that restricts entry. Besides, it gives better access to well-heeled rich-country groups like the Sierra Club with their army of lawyers and their rich-country perspectives. So there should be free entry: a website perhaps, to which anyone can send in their briefs. As for such briefs being invited by the panel or the appellate court, there must be a balance between briefs from the developing and the developed countries or else the interests of the developing countries will be compromised.

I would even go so far as to consider remedies that remove the inequities of the adversarial system, where rich countries can spend huge sums on their side but the poor countries are constrained by the limited resources available to them. Why not get a rich country to give to the poor countries against which it is bringing a case a sum that matches its own estimated legal expenses, so that the contest is equal? The liberal establishment in US law schools should find this and other remedies (perhaps a limit on what might be spent relative to what the poor defendant can afford) to the unbalanced battles between the rich and the poor a matter of some interest.

As for the trade negotiations, it is evident that it is up to the governments that negotiate to give their preferred NGOs, business and union lobbies a place on their negotiating teams. To give the NGOs a second shot independent of the governments which they have elected has no rationale; it also serves to give the rich-country negotiators added weight because it is the rich-country NGOs that are effectively going to have a greater voice, given their greater resources of money, clout and lobbying experience.

As for the secretariat, there are now several opportunities for regular contact with civil society groups through seminars and conferences (though the appalling way in which the Quad countries [EU, USA, Japan and Canada] have starved the WTO of money for staff and work-related seminars while pouring huge amounts of money wastefully into the IMF and the World Bank, which they control better, is a scandal of which few are aware). That is a good thing. But perhaps it needs to be more institutionalized, again with balanced representation from the developing and the developed countries, and with adequate regular funding. 